\title{
Liver function test as a marker for acute appendicitis Yadav $\mathbf{S}^{1}$, Chandra $\mathrm{K}^{2}$
}

\author{
Department of Surgery, Janaki Medical College \\ Ramdaiya, Janakpur, Nepal
}

${ }^{1}$ Assistant Prof, Department of Surgery, Janaki Medical College, Janakpur, Nepal

2Prof., Department of surgery, UCMS, Bhairahawa, Nepal

\begin{abstract}
Background and Objectives: Acute appendicitis is one of the commonest surgical emergencies of the abdomen worldwide. Even with the availability of current imaging investigation like USG , CT scan and MRI, the diagnosis is still a problem. Delay in diagnosis increases mortality and morbidity. Liver function test is one of the biochemical parameters being assessed as a marker of acute appendicitis and may also predict the severity of the inflammation. However the available literature is limited and views are conflicting. In this study, it is proposed to access the validity of using liver function test to predict the appendicitis and its severity.

Material and Methods: This is a prospective study of 80 cases of operated patients of acute appendicitis in Universal College Of Medical Sciences, Bhairahawa, Nepal during the period from 6th May 2013 to 6th July 2014. Data were collected from the patient by their clinical history, examination and investigations, Liver function test and ultrasound. Post operative follow up was done to note for complications and histopathology findings. Data collection was compiled in a systemic way in preformed proforma and analyzed.
\end{abstract}

Results: Out of 80 patients, 44(55\%) were male and 36(45\%) were female. Total serum bilirubin was elevated in 29 (36.25\%) of the patients. Rise in serum bilirubin was mixed type with direct bilirubin Predominance. In Liver enzymes ALT, AST, ALP were raised in 32.5\%, 28.75\% and 82.5\% respectively. Hyperbilirubinemia has the specificity (80 \%) sensitivity (37.33\%) with good positive predictive value of $96.55 \%$. Similarly sensitivity and specificity of direct bilirubin $(90.67 \%, 20.00 \%)$, Indirect bilirubin $(16.00 \%, 80 \%)$, AST/SGOT (30.67\%, 100\%), ALT/SGPT $(34.67 \%, 100 \%)$ ALP $(84.00 \%, 40 \%)$ respectively. The positive predictive value for direct bilirubin, indirect bilirubin, AST/SGOT, ALT/SGPT and ALP are 94.44\%,92.31\%,100\%,100\% and 95.45\% respectively.

Conclusion: Liver function test is a marker for acute appendicitis and its complication with a good positive predictive value. Liver function test should be used together with clinical examination and other laboratory investigations in the assessment of patients with suspected acute Appendicitis.

Key words: Acute appendicitis, Liver function test,

\section{INRODUCTION}

Acute Appendicitis is one of the most common surgical emergencies with life time prevalence rate of approximately one in seven [1]. The incidence is 1.5 - 1.9 per 1000 in the population and is approximately 1.4 times greater in men than in women [2]. The 
diseases occurs at all ages but is most frequent in the 2nd and 3rd decades of life [3].

Though most commonly performed surgery of the abdomen, it is still difficult to diagnose thereby leading to high negative appendectomy rate with the delayed diagnosis depending on clinical acumen alone leads to increased mortality and morbidity [4-6]. Diagnosis of acute appendicitis remains a surgical dilemma, with negative appendectomy rates of $5 \%$ to $40 \%$ and perforation suggestive for late operative intervention in $5 \%$ to $30 \%$ [7]. Many surgeons will accept a certain rate of negative laparotomy in order to avoid missing an inflamed appendix and its complications like perforation [8].

The higher awareness about diseases and its complications, higher access to health care and health insurance in the developed countries has shown fewer complications of the appendicitis with early detection and surgery following acute symptoms. But the situation is different in developing nations where poverty, illiteracy and high cost of medical treatment make them slow to report to health facility leading to high complications [9].

Appendicitis is notorious in its ability to simulate other conditions and in the frequency it can be mimicked by other pathological conditions. The diagnosis of acute appendicitis is based purely on clinical history and examination combined with minimal laboratory investigations such as elevated white cell count. Despite being a common problem diagnosis of the acute appendicitis remains difficult to establish, particularly among the young, the elderly and females of reproductive age, where a lots of other genitourinary and gynaecological inflammatory conditions can present with signs and symptoms that are similar to those of acute appendicitis [10]. CT scan is a reliable diagnostic modality but has limitations like increased radiation and cost. No reliable specific marker for acute appendicitis has been identified. Even none of the clinical or laboratory test is able to reliably predict acute appendicitis. Therefore much interest exists in finding ways to diagnose and estimate the extent of acute appendicitis before relying on radiological test [11]. A simple cheap biochemical test that is specific for acute appendicitis useful in conjunction with clinical finding in predicting diagnosis of appendicitis or appendicitis with its complication needs to be evaluated for surgical decision $[12,13]$.

Liver function test is one of the biochemical parameters being assessed as a marker of acute appendicitis and may also predict the severity of the inflammation. However the available literature is limited and views are conflicting. In this study, it is proposed to access the validity of using liver function test to predict the appendicitis and its severity.

\section{MATERIALS AND METHODS}

This is a prospective analytical study of 80 cases of operated patients of acute appendicitis in Universal College of Medical Sciences, Bhairahawa, Nepal during the period from 6th May 2013 to 6th July 2014. The cases were selected by following selection criteria.

\section{Selection criteria}

\section{Inclusion Criteria}

1. All operated patients of acute appendicitis. 
2. All patients who agreed to participate in study and given a written consent.

\section{Exclusion Criteria}

1. Documented biliary, Hemolytic or liver disease.

2. History of jaundice.

3. History of alcoholism.

4. History of blood transfusion and hepatotoxic medication

Data were collected on preformed proforma during the stay in the hospital from the patient by their clinical history; examination and investigations including liver function test and ultrasound. Post operative follow up was done to note for complications and histopathology findings. Data collection was compiled in a systemic way in preformed proforma and analyzed using SPSS ver. 20. The major focus was on liver function test (unconjugated bilirubin, conjugated bilirubin, alkaline phosphatase, SGOT, SGPT) acute appendicitis and its histology.

\section{RESULTS}

A total of 80 patients were enrolled for the study that had been operated for Acute Appendicitis. Out of 80 cases studied, 44 cases (55\%) were males and females accounting for 36 cases (45\%).

Fig no 1: Diagram showing distribution of case as per USG Finding

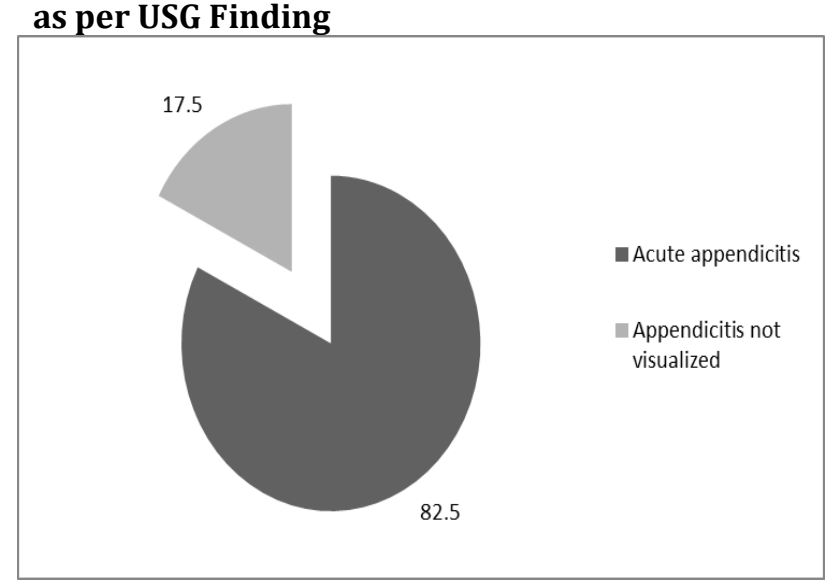

Male to Female ratio was 1.22:1. The Age group most commonly involved was 11-20 years followed by 21-30 years. The minimum age is 8 years and maximum age is 70 years.

All 80 patients were subjected for ultrasound examination, out of which 66 case showed acute appendicitis where as in 14 cases appendix was not visualized (Fig 1). Table 1 reveals the descriptive statistics of liver function tests among 80 patients.

Table 1 showing descriptive statistics of Liver Function Test (LFT)

\begin{tabular}{|c|c|c|c|}
\hline LFT & Mean \pm SD & Min & Max \\
\hline Total Bilirubin & $1.15 \pm 0.57$ & 0.3 & 3 \\
\hline Direct Bilirubin & $0.56 \pm 0.32$ & 0.1 & 1.6 \\
\hline Indirect Bilirubin & $0.58 \pm 0.31$ & 0.2 & 1.7 \\
\hline SGOT/AST & $42.06 \pm 34.17$ & 10 & 223 \\
\hline SGPT/ALT & $32.89 \pm 32.08$ & 6 & 272 \\
\hline ALP & $239.34 \pm 89.55$ & 80 & 570 \\
\hline
\end{tabular}

Figure 2: showing histopathological findings

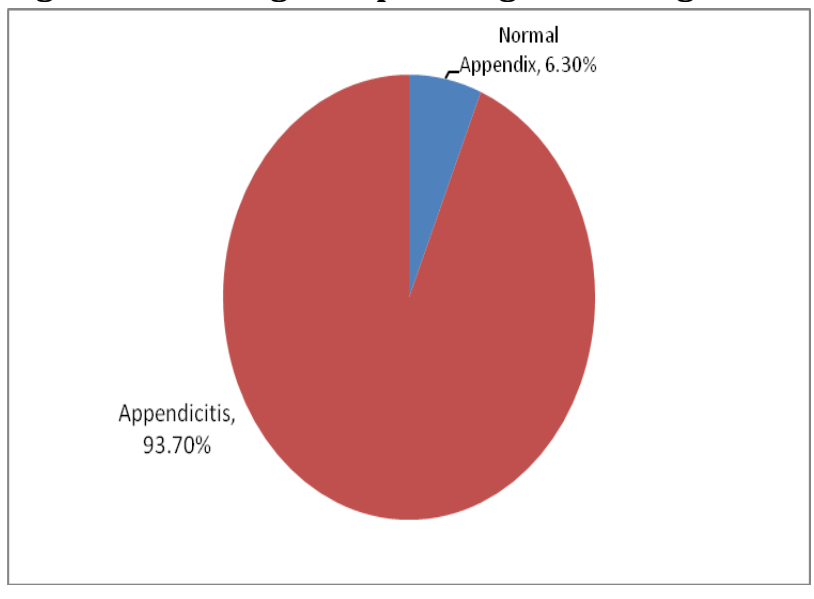

Figure 2 depicts distribution of histopathological findings. Normal appendix was seen in 5 cases $(6.3 \%),(n=80)$ where as $75(93.7 \%)$ cases were of appendicitis. 
Table 3: Liver Function Test and Histopathology (Appendicitis and Normal Appendix) in cross tabulation

\begin{tabular}{|c|c|c|c|c|}
\hline \multirow{2}{*}{$\begin{array}{c}\text { Liver } \\
\text { function } \\
\text { Tests }\end{array}$} & \multicolumn{2}{|c|}{ Histopathology } & \multirow[t]{2}{*}{ Total } & \multirow{2}{*}{$\begin{array}{l}\text { Sensitivity/Spec } \\
\text { ificity/ Positive } \\
\text { Predictive value }\end{array}$} \\
\hline & $\begin{array}{l}\text { Appen } \\
\text { dicitis }\end{array}$ & $\begin{array}{c}\text { Normal } \\
\text { Append } \\
\text { ix }\end{array}$ & & \\
\hline \multicolumn{5}{|l|}{$\underline{\text { Total }}$} \\
\hline Elevated & 28 & 1 & 29 & \multirow{3}{*}{$\begin{array}{c}\text { Sensitivity }=37.33 \\
\%, \\
\text { Specificity }=80 \% \text {, } \\
\text { Positive } \\
\text { Predictive value } \\
=96.55\end{array}$} \\
\hline Normal & 47 & 4 & 51 & \\
\hline Total & 75 & 5 & 80 & \\
\hline \multicolumn{5}{|l|}{$\begin{array}{c}\text { Direct } \\
\text { Bilirubin }\end{array}$} \\
\hline Elevated & 68 & 4 & 72 & \multirow{3}{*}{$\begin{array}{c}\text { Sensitivity }=90.67 \\
\%, \\
\text { Specificity }=20 \% \text {, } \\
\text { Positive } \\
\text { Predictive value } \\
=94.44\end{array}$} \\
\hline Normal & 7 & 1 & 8 & \\
\hline Total & 75 & 5 & 80 & \\
\hline \multicolumn{5}{|l|}{ 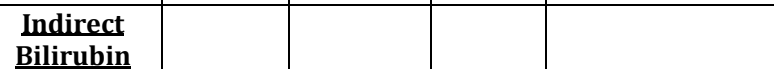 } \\
\hline Elevated & 12 & 1 & 13 & \multirow{3}{*}{$\begin{array}{l}\text { Sensitivity }=16 \% \text {, } \\
\text { Specificity }=80 \% \text {, } \\
\text { Positive } \\
\text { Predictive value } \\
=92.31\end{array}$} \\
\hline Normal & 63 & 4 & 67 & \\
\hline Total & 75 & 5 & 80 & \\
\hline \multicolumn{5}{|l|}{ SGOT/AST } \\
\hline Elevated & 23 & 0 & 23 & \multirow{3}{*}{$\begin{array}{c}\text { Sensitivity }=30.67 \\
5 \%, \\
\text { Specificity }=100 \\
\% \text {, Positive } \\
\text { Predictive value } \\
=100\end{array}$} \\
\hline Normal & 52 & 5 & 57 & \\
\hline Total & 75 & 5 & 80 & \\
\hline \multicolumn{5}{|l|}{$\underline{\text { SGPT/ALT }}$} \\
\hline Elevated & 26 & 0 & 26 & \multirow{3}{*}{$\begin{array}{c}\text { Sensitivity }=34.67 \\
\%, \\
\text { Specificity }=100 \\
\% \text {, Positive } \\
\text { Predictive value } \\
=100\end{array}$} \\
\hline Normal & 49 & 5 & 54 & \\
\hline Total & 75 & 5 & 80 & \\
\hline \multicolumn{5}{|l|}{$\underline{\text { ALP }}$} \\
\hline Elevated & 63 & 3 & 66 & \multirow{3}{*}{$\begin{array}{c}\text { Sensitivity }=84 \% \text {, } \\
\text { Specificity }=40 \% \text {, } \\
\text { Positive } \\
\text { Predictive value } \\
=95.45\end{array}$} \\
\hline Normal & 12 & 2 & 14 & \\
\hline Total & 75 & 5 & 80 & \\
\hline
\end{tabular}

Serum Total Bilirubin: $<=1.1$ Normal , $>1.1$ Elevated Serum direct Bilirubin: $<=0.2 \mathrm{mg}$ Normal, $>0.2 \mathrm{mg}$ Elevated Indirect Bilirubin $:<=0.9 \mathrm{U} / \mathrm{L}$ Normal, $>0.9 \mathrm{U} / \mathrm{L}$ Elevated Liver Enzymes: SGOT/AST < $=40 \mathrm{U} / \mathrm{L}$ Normal, $>40 \mathrm{U} / \mathrm{L}$ Elevated Liver Enzymes: SGPT/ALT<=35U/L Normal, >35U/L Elevated Liver Enzymes: ALP

\section{DISCUSSION}

In current study, ultrasonography was positive for acute appendicitis in 66 patients (82.5\%). This value is similar to that found by Lohani B et.al [14].

Normal appendix was seen in Histopathological findings of 5 cases $(6.3 \%)$ out of 80 cases. This is less with observations of M. Sand et. al. who reported $12.45 \%$ (67 out of 538) of normal appendix [15]. Dhakal et. al. reported $22.7 \%$ of case of negative appendectomy [6]. But more than that of reported by Subedi et. al. $1.4 \%$ (5 case) of normal appendix in histopathological finding out of 345 case [16].

The Present study has shown male preponderance with $55 \%$ case of Acute Appendicitis with male to female ratio of 1.2:1. Similar observation of male preponderance with ratio of 1.7:1 were also made by one of the hospital based study done in Nepal [17].

In current study, serum bilirubin raised in $36.25 \%$ ( 29 cases) i.e more than $1 / 3$ rd of case of Acute Appendicitis. It ranged from $0.3 \mathrm{mg} / \mathrm{dl}$ to $3 \mathrm{mg} / \mathrm{dl}$ and median is $1.11 \mathrm{mg} / \mathrm{dl}$. Conjugated bilirubin raised in 72 (90\%) case where as serum unconjugated bilirubin raised on 13(16.75\%). In, hyperbilirubinemia, conjugated type is predominant. Estrade et al. had also shown hyperbilirubinemia $59(38 \%)$ of 157 patients i.e 1/3rd of case of Acute Appendicitis [18]. Andrew Emmanuel et.al. showed 30\% of patients of hyperbilirubinemia in case of simple acute appendicitis [11].

Also, observation of hyperbilirubinemia of $24.9 \%$ of patients, range 0.1-4.3 $\mathrm{mg} / \mathrm{dl}$,median $0.7 \mathrm{mg} / \mathrm{dl}$ reported by Sand, et.al. [15]. Similarly, Kaser et al. also have shown $38 \%$ case of hyperbilirubinemia in case of acute appendicitis [19]. Whereas Young et.al [20] showed less than current study $17.66 \%$ (211 patients out of 1,195 ) case of acute appendicitis had raised 
bilirubin. Khan (2008) found serum bilirubin raised in majority of cases $86.60 \%$ of patients. Hyperbilirubinemia was of mixed type and also predominantly of conjugated type [21]. Mahammad et.al. showed $57.70 \%$ i.e. 41 in 71 of patients had raised serum bilirubin. [22].

The present study has shown sensitivity, specificity, positive predictive value of total bilirubin $\quad 37.33 \%, \quad 80.00 \%, \quad 96.55 \%$ respectively in case of appendicitis with direct bilirubin had higher sensitivity than direct bilirubin. Similar very close observation was showed by Andrew Emmannel et. al. i.e. total bilirubin sensitivity $30 \%$, specificity $88 \%$ and positive predictive value 91\%. [11]. Also, Kaser et al. showed total bilirubin sensitivity 38\%,specificity $78 \%$, positive Predictive value 32\% [19], where as Young et. al. showed bilirubin sensitivity $55.92 \%$ and specificity $66.11 \%$ [20].

Similarly, Our result was inconsistent with observation of Atahan et. al. has shown bilirubin sensitivity $77.77 \%$, specificity $87.21 \%$ with positive predictive value $45.16 \%$ [23]. And Sand et.al. showed specificity of bilirubin $86 \%$,sensitivity $70 \%$ with positive predictive value $51 \%$ [15].

AST in current study raised in 23 (28.75\%) case,ranged from 10 to $223 \mathrm{U} / \mathrm{L}$, average level $42.06 \mathrm{U} / \mathrm{L}$ and S.D 34.17 with positive predictive value of $100 \%$. ALT raised in 26 (32.5\%) case, range 6 to $272 \mathrm{U} / \mathrm{L}$, average level $32.89 \mathrm{U} / \mathrm{L}$ and S.D 32.08 with positive predictive value of $100 \%$. Age and sex adjusted ALP elevated in $82.5 \%$ of case with positive predictive value of $95.45 \%$.

Similarly, Khan (2008) showed AST elevated in $38.77 \%$ of case, , ALT elevated in $26.54 \%$ of case and ALP elevated in $48.97 \%$ of case [21]
And Sand et.al showed an average level of AST 21.5 U/L,ranged 5-26U/L and S.D 19.2. and average level of ALT $21.8 \mathrm{U} / \mathrm{L}$,ranged 7133U/L and S.D 11.1 [15].

As a summary, Hyperbilirubinemia have the highest specificity $(80.00 \%)$ than sensitivity $(37.33 \%)$ with good positive predictive value of $96.55 \%$. Similarly, sensitivity, specificity and positive predictive value for prediction of appendicitis by Direct bilirubin, Indirect bilirubin, AST/SGOT, ALT/SGPT and ALP are (90.67\%, 20.00\%, 94.44\%), (16.00\%, 80.00\%, $92.31 \%), \quad(30.67 \%, \quad 100.00 \%, \quad 100.00 \%)$, $(34.67 \%, \quad 100.00 \%, \quad 100.00 \%), \quad(84.00 \%$, $40.00 \%, 95.45 \%$ ) respectively.

\section{CONCLUSION}

Liver function test is a marker for acute appendicitis and its complication with a good positive predictive value. Liver function test should be used together with clinical examination and other laboratory investigations in the assessment of patients with suspected acute Appendicitis.

\section{ACKNOWLEDGEMENT}

We are grateful to all the members of Department of Surgery Universal College Of Medical Sciences, Bhairahawa Nepal for their support.

\section{REFERENCES}

1. Nikolaidis P, Hwany MC, Millr HF and Papanicolaon N. The Non Visualized Appendix: Incidence of Acute Appendicitis When Secondary Inflammatory Changes. ARC Absent 2004; 183: 889-992.

2. Cusheri A. The small intestine and vermiform appendix. In: Cushieri A, Giles GR, MossaAR, eds. Essential Surgical practice. 3rd ed. Oxford: Butterworth-Heinermann; 1995. pp1297-329.

3. Korner H ,Sondenaa K , Soreide AJ. Incidence of Acute Non-perforated and perforated 
Appendecitis: Age-specific and Sex-specific Analysis. World J surg 1997; 21: 313-317.

4. Wente MN et al. Strategy for avoidance of negative appendectomies. Chirurg 2009 : 80(7): 588-953

5. Edino ST. Mohammed AZ, Orchicha O, Anumah M. Appendicitis in Kano,Nigeria Anumah $\mathrm{M}$. Appendicitis in Kano,Nigeria 95 year review of Pattern,morbidity and mortality: Ann Afr Med 2004,3: 38-41.

6. Dhakal RR et.al. When it was not AppendicitisRetrospetive review of 392 appendectomies. J of Gandaki Medical college Nepal 2010; 13(1): 4-8.

7. Thuijls G, Derikx JP, Prakken FJ, Hyisman B, Van BIAA, Van HEL et al. A pilot study on potential new plasma markers for diagnosis of acute appendicitis. Am J Emerg Med 2011; 29: 256-260.

8. Abu-Eshy SA, Ibn ouf MA, Malatani TS et al. Acute Appendicitis in females a clinical study of 366 cases. Afr J Med Sci 1995; 24:227-230.

9. Afridi SP, Malik F, Rahmans et al. Spectrum of perforation peritonitisn Pakistan: 300 cases Estern experience. World J Emerg Surg 2008; 3:31-37.

10. Gilmore OJ, Browett JP, Griffin PH et al. Appendicitis and mimicking conditions: A prospective study. Lancet 1975; 2: 421-424.

11. Emmannel A, Murchan $P$ et al The value of hyperbilirubinemia in the diagnosis of acute appendicitis. ANN R Coll Surg Engl 2011; 93: 213217

12. Khan S. Evaluation of hyperbilirubinemia in acute inflammation of appendix: A prospective study of 45 cases. Kathmandu Univ Med J 2006; 4(3): 281289

13. Sahm M, Pross M, Lippert H. Acute appendicitis changes in epidemiology, diagnosis and therapy. Zentralbl Chir 2011; 136: 18-24

14. Lohani B, Gurung G, Paudal S, Kayastha P. Diagnostic efficacy of ultrasonography in acute appendicitis. Journal of institute of Med 2012; 34(3): 8-11.

15. Sand M, Bechara FG, Holland-Letz T, Sand D, Mehnert G, Mann B. Diagnostic value of hyperbilirubinemia as a predictive factor for appendiceal perforation in acute appendicitis. Am J Surg 2009; 198: 193-198

16. Subedi N, Dangol VS, Adhikary MB, Pudasaini S, Baral R. Acute Appendicitis a 2-year review of clinical presentation and histopathology. Journal of pathology of Nepal 2011; 1: 104-107.

17. Malla BR, Shrestha RKM. Appendicular perforation. J of Institute of Med 2011; 33(1): 1415.
18. Estrada JJ, Petrosyan M, Barnhart $\mathrm{J}$ et al. Hyperbilirubinaemia in appendicits: A new predictor of perforation. J Gastroenterol 2007; 11: 714-718.

19. Kaser SA, Fankhauser G et al. C-reactive protein is superior to bilirubin for anticipation of perforation in acute appendicitis. Scand J. Gastroenterol 2010; 45(7-8): 885-92.

20. Hong R , Chuung WC et al. Hyperbilirubinemia is a significant indicator for the severity of acute appendicitis. J Korean society coloproctol 2012; 28(5) : 247-252.

21. Khan S. Effect of Acute appendicitis on routine Liver function Tests. J of institute of med 2008; 30 : 141-45.

22. Muhammad JS, Mohammad AH, Ahmad $\mathrm{H}$. Hyperbilirubinemia a Predictive factor for complicated acute appendicitis: a study in a tertiary care hospital. J Pak Med Assoc 2013; 63(11):1374-1378.

23. Atahan $\mathrm{K}$, Ureyen $\mathrm{O}$ et al. Preoperative diagnostic role of hyperbilirubinemia as a marker of appendix perforation. J Int Med Res 2011; 39(2): 609-618. 